\title{
Changes in Naming and Cognitive Abilities as the Effects of Semantic Feature Analysis Treatment in Middle-Aged and Older Adults
}

\author{
JungWan Kim ${ }^{\mathrm{a}}$, Yeonwook Kang ${ }^{\mathrm{b}}$, Ho-Young Lee ${ }^{\mathrm{c}}$, Jaihyun Kim ${ }^{\mathrm{d}}$, Ji Hye Yoon ${ }^{\mathrm{e}}$ \\ ${ }^{a}$ Department of Speech Pathology, Daegu University, Gyeongsan, Korea \\ ${ }^{b}$ Department of Psychology, Hallym University, Chuncheon, Korea \\ 'Department of Nuclear Medicine, Seoul National University College of Medicine, Seoul, Korea \\ ${ }^{d}$ Department of Industrial Management and System Engineering, Seokyeong University, Seoul, Korea \\ ${ }^{e}$ Division of Speech Pathology and Audiology, Hallym University, Chuncheon, Korea
}

Correspondence: Ji Hye Yoon, $\mathrm{PhD}$

Division of Speech Pathology and Audiology,

Hallym University, 1 Hallimdaehak-gil, Chuncheon

24252, Korea

Tel: +82-33-248-2224

Fax: +82-33-256-3420

E-mail: j.yoon@hallym.ac.kr

Received: December 27, 2018

Revised: February 4, 2019

Accepted: February 20, 2019

This research was supported by 2018 Hallym University Research Fund (No. HRF-201810-012).

This work was supported by the National Research Foundation of Korea grant funded by the Korean government (No. NRF-2014S1A5A2A03065709).

\begin{abstract}
Objectives: Difficulty in word finding and retrieval frequently occurs during the normal aging process. Interventions in middle-aged or elderly adults in the preclinical stage may possibly improve naming ability and further promote brain function in terms of brain plasticity and functional reorganization. If so, this intervention can be used not only to treat communication disorders among middle-aged or older dementia patients, but also to prevent cognitive decline. The aim of the study was to investigate the effect of a semantic feature analysis intervention program in middle-aged and older adults with subjective or objective naming difficulties. Methods: Forty-two participants, aged 55 to 84 years, were screened using a cognitive communication test and divided into two groups of healthy and abnormal participants using the Korean Boston Naming Test (K-BNT) criteria. All participants received a total of 20 sessions of intervention using open-ended induction questions by semantic category and home assignment using a grid. Neuropsychological evaluations and detailed language evaluations were conducted before and after the intervention to assess behavioral changes. Results: All participants had better accuracy on the KBNT and better accuracy and reaction time in the post-treatment probe test than in the pre-treatment condition regardless of objective naming difficulty. In addition, with regard to cognitive functions, significant improvements in the word fluency test (phonemic) and verbal learning test (immediate and delayed recalls) were observed. Conclusion: The results suggest that word finding difficulties or naming impairments can be improved by activating the network for the whole semantic system.
\end{abstract}

Keywords: Semantic feature analysis, Middle-aged and older adults, Word retrieval, Activation
우리나라는 65세 이상이 차지하는 비율이 2009년을 기준으로 $10.7 \%$ 에 달하였으며, 2017년 8월을 기점으로 고령화 사회를 넘어 고령사회(65세 이상 인구가 전체 인구의 $14 \%$ 이상)로 들어섰다(Ministry of the Interior and Safety, 2017). 신체생리적 변화 측면에서 장 노년층은 청년층과 비교하여 전체적인 뇌의 크기가 줄어들며, 뇌실 의 크기가 확장되는 양상을 보인다(Buckner, Head, \& Lustig, 2006; Burda, 2011). 이러한 뇌의 구조적인 변화는 인지 및 언어능력에도
영향을 준다(Burda, 2011; Mun, 2001).

장노년층이 일상생활에서 흔히 경험하는 문제는 생각이 날 듯 말 듯 하면서 혀끝에서 단어가 맴도는 듯 하는 단어 찾기 어려움 (word finding difficulty)이 증가하는 것이다. 해당 단어를 원활히 산출하지 못하는 것은 장노년층을 당혹스럽게 하지만(Lovelace \& Twohig, 1990) 종종 단어가 “불쑥 생각나면서(pop-up)” 해결된다. 이는 산출하려고 시도하지 않아도 목표어가 갑자기 자기도 모르게 
산출되는 것이다(Cohen \& Faulkner, 1986). 따라서 충분한 시간이 주어졌을 때, 이것이 해소될 수 있다는 것은, 산출하려는 단어 자체 를 잊어버린 것이 아니라, 인출능력이 저하되어서 회상하는 데 오랜 시간이 걸리기 때문임을 시사한다(Heine, Ober, \& Shenaut, 1999). 청년층과 비교하여 노년층에서 이러한 현상이 빈번히 발생하는 원 인은 노화로 인한 음운적 어휘집(phonological lexicon)으로의 접 근이나 연결이 약화되기 때문으로 보았다(Burke, Mackay, Worthley, \& Wade, 1991; Cohen \& Faulkner, 1986). 이런 경우는 구어표현 이 더디기는 하나 결과적으로 표현하고자 하는 단어 산출을 실패하 는 것은 아니기 때문에 의사소통에 유의한 걸림돌이 되지는 않는다.

그러나 단어 찾기 어려움에서 더 나아가 이것이 이름대기의 실패 혹은 이름대기 장애(naming impairment)로 이어지게 되면 문제는 달라진다. 노화가 진행될수록 고유명사나 저빈도 단어를 산출할 때 어려움을 겪거나 의미착어를 보이고(Burda, 2011; Mortensen, Meyer, \& Humphreys, 2006), 단어를 재인하여 처리하는 속도가 늦어지며(Ratcliff, Thapar, Gomez, \& McKoon, 2004), 대면이름대 기 과제에서의 수행력이 저하되고 느린 산출 속도를 보인다(Barresi et al., 2000; Kim, Hwang, Kim, \& Kim, 2013; Mortensen et al., 2006). 또한 단어에 대한 의미지식을 반영하는 단어정의하기 과제의 수행 력을 통해 노년층의 이름대기 능력이 저하되는 원인을 의미처리 능 력의 감소에 기인한 것으로 설명하기도 하였다(Bowles \& Poon, 1985; Kim \& Choi, 2012). 이러한 이름대기 장애의 경우에는 충분 한 시간을 주어도 스스로 단어 산출을 하지 못하기 때문에 구어 표 현에 문제가 있는 장노년층은 사회활동과 그들이 전에 즐기던 활동 에 대한 시도들로부터 점차 멀어지게 되어서 삶의 질이 저하되기도 한다. 또한 이름대기 장애는 언어장애에 속하지만 장노년층은 이를 기억장애로 여기고 치매의 초기 증상이 아닐지 불안해 할 뿐만 아 니라 이로 인해서 의사소통의 불편함을 느끼고 대인관계에서도 철 회되는 경향이 있다. 따라서 우리는 노화 과정에 따른 이름대기 능 력의 저하에 주목할 필요가 있다.

최근에는 노화로 인한 신체생리적 변화를 이해하려는 노력이 기 능 저하뿐만 아니라 비약리적 중재(non-pharmacological intervention)를 통한 인지 및 언어능력의 개선으로도 옮겨가고 있다. 경도인 지장애(mild cognitive impairments, $\mathrm{MCI}$ )와 치매 환자를 대상으 로 비약리적 중재를 통해 언어 및 인지능력을 증진시킨 연구들(Barnes et al., 2009; Belleville et al., 2006; Carretti, Borella, Fostinelli, \& Zavagnin, 2013; Jang, Lee, Kim, \& Jeon, 2012; Lee \& Kim, 2013)의 이론적 배경은 뇌가소성(cerebral plasticity) 및 기능적 재조직화 원 리를 통한 중추신경계 기능의 회복과 연습이 인지적 퇴행의 감소 와 환자의 비축 능력(reserve capacity)을 활용한 환경적 적응을 가
능케 한다는 것이다(Galante, Venturini, \& Fiaccadori, 2007). 이러 한 관점에서 지역사회 장노년층에게 이름대기 장애에 대한 중재를 실시하여 언어와 인지능력을 증진시킬 수 있다면 향후 인지의사소 통장애의 발생 가능성을 줄이고 예방할 수 있는 한 방법이 될 수 있 을 것이다.

이름대기 중재는 크게 음운적 접근과 의미적 접근으로 나뉜다. 음운적 접근은 중재의 방법이라기보다는 단서로서 사용되는 경우 가 많은데, 의미체계에 손상이 없고 어휘에 해당하는 음운적 정보 의 산출에 어려움을 보이는 환자에게 음운 단서 등을 제시하여 단 어를 산출할 수 있도록 돕는 것이다. 그러나 음운 단서 등을 통한 중 재는 일반화의 효과가 크지 않다는 점에서 중재 실효성에 관한 임 상적 논의가 지속되어오고 있다(Kim, 2012). 또 다른 접근방법으 로는 이름대기 이론 중 비교적 최근에 대두된 가설인 활성화 확산 이론(spreading activation theory)에 기초를 둔 중재방법인 의미자 질분석(semantic feature analysis, SFA)이 있다(Collins \& Loftus, 1975). 이 방법은 다각적인 과제를 통해 의미체계를 자극하는 것으 로, 이는 의미체계를 비롯하여 많은 마디(node)들이 서로 연결을 이루고 있고, 연결된 각 마디들은 일방향의 처리를 하는 것이 아니 라 서로에게 영향을 주고받으면서 전반적인 의미체계상의 네트워 크를 활성화하게 되어, 목표단어를 산출한다고 주장한다(Boyle \& Coelho, 1995). 그러므로 의미체계를 활성화시키는 것은 결국 모든 언어와 연관된 마디에 긍정적 영향을 주고받으면서 점화(prime)된 다는 것이다. 결과적으로, 다각적인 점화로 기저의 체계에 접근하 면서 이름대기 산출과정 전반에 걸쳐 활동성을 증가시키는 SFA는 기억 속의 정보가 범주화되어 저장되는 것을 이용한 전략으로, 개 인의 기본 지식과 범주화한 개념들을 이용해 어휘 습득효과를 증 진시킨다. 장노년층은 의사소통 상황이나 이름대기 평가 시에 목표 어 산출이 원활하지 않을 때 의미적 오류나 에두르기, 단어의 범주 나 의미자질 등을 이야기하면서 낱말의 음운정보를 산출하려는 시도를 보인다(Burda, 2011). 이는 목표어의 원활한 인출을 위해서 는 목표단어 주위에 있는 의미네트워크의 활성화가 동반되어야 함 을 시사하는 것이다. 이를 역으로 생각해보면, 단어 인출이 어려울 때 목표어와 관련된 의미자질을 산출하도록 하고 관련된 의미자질 로 접근하는 전략의 사용을 자동화시킴으로써 노화과정에서 관찰 되는 이름대기의 어려움을 해결할 수 있음을 내포한다.

그동안 이루어진 SFA 중재연구를 살펴보면 어휘의미체계에 손 상에 대항하여 실어증 환자의 이름대기 능력의 향상과 유지를 가 능케 한다고 그 효과가 보고되었으나(Boyle, 2004; Boyle \& Coelho, 1995; Coelho, McHugh, \& Boyle, 2000; Conley \& Coelho, 2003; Kiran \& Thompson, 2003; Law, Wong, Sung, \& Hon, 2006; Rider, 
Wright, Marshall, \& Page, 2008; Wambaugh, Mauszycki, Cameron, Wright, \& Nessler, 2013) 중재 연구의 여건상 10 명 이하의 대상 자로 진행되어 다수의 대상자 적용에 대한 필요성과 함께 대상자 간의 언어능력이 통제되지 못하였음을 연구의 제한점으로 밝히고 있다. 최근에는 의미체계의 손상에 기인한 알츠하이머형 치매(dementia of the Alzheimer's type, DAT) 환자(Kang, Sung, \& Lee, 2015; Mo, Sung, \& Jeong, 2015)에서도 SFA의 효과가 증명되었다. 그러나 참여자 수가 적고 이미 퇴행의 임상적 단계에 진입한 질환 군을 대상으로 하였기 때문에 일반화 효과가 일정하지 않았다. 이 를 재고하여 일상생활기능에 문제가 없이 지역사회에서 생활하고 있고 전반적인 인지능력이 유지되고 있으나 이름대기 문제를 주관 적으로 호소하는 장노년층 대상자들에게 SFA중재의 적용가능성 을 탐색하고, 그 효과를 일반화할 수 있다면 SFA 중재를 퇴행의 예 방적인 차원에서도 활용할 수 있을 것이다.

따라서 본 연구에서는, 일상생활기능을 잘 유지하고 있고 인지기 능의 저하나 장애를 이유로 병원에 내원한 적은 없으나 주관적으 로는 이름대기 능력의 저하를 느끼고 있는 지역사회 장노년층을 대 상으로 SFA 중재효과를 확인하고자 하였다. 중재 전에 대상자들의 이름대기 능력의 정상 여부를 객관적으로 평가하여 대상자를 이름 대기 정상집단과 이상집단으로 나누었다. SFA 중재프로그램을 4주 간 실시한 후 두 집단 각각의 SFA 중재효과 여부와 두 집단의 중재 효과가 차이가 있는지 중재 전후 대면이름대기검사의 수행력을 비 교하여 확인하였다. 또한 SFA는 인지언어에 기반한 이름대기 중재 법으로 다각적인 점화를 통해서 기저 체계에 접근하여 이름대기 산출과정 전반의 활동성을 증가시키는 전략이므로 이와 관련한 인 지기능을 추가적으로 확인할 필요가 있다. 이에 다양한 인지기능 검사 중 수행에 있어 단어의 인출능력(이름대기능력/단어찾기능 력)의 영향을 많이 받는 것으로 알려진 통제단어연상검사와 언어 적 기억력 검사(Melrose et al., 2009)를 실시하고 중재에 따른 이들 검사의 수행 변화 정도를 확인하였다.

\section{연구방법}

\section{연구대상}

본 연구의 중재 대상자는 서울 및 경기, 강원, 경상 지역의 노인복 지관, 마을회관, 개인 동호회 등을 통하여 모집되었다. 연령 기준은 고령자 고용촉진법의 55 세 이상, 국민연금법의 60 세 이상, 노인복지 법의 65세 이상을 절충하되, 노년층 진입 전 단계에서 효과적으로 이름대기 장애를 중재하기 위한 목적으로 가장 젊은 연령인 55세 부터 84세 사이의 장노년층을 본 연구의 대상자로 하였다. 먼저 55-84
세 사이의 장노년층 273 명(남자 105 명, 여자 168 명)에게 본 연구의 내용을 설명한 뒤, 동의서에 서명한 피험자들을 대상으로 면담과 선별 인지언어검사를 시행하였다. 그 후 선정기준에 따라 모든 여 건을 만족하면서 치료에 동의 의사를 표시하는 경우 프로그램 대 상자로 선정하였다.

대상자는 (1) 인지기능 감퇴와 연관된 29가지 질병 여부를 확인 하는 설문지(Christensen, Multhaup, Nordstrom, \& Voss, 1991)를 통해 일차적으로 인지능력에 영향을 미칠 수 있는 질병의 병력이 없는 자, (2) 단축형 노인우울척도(Short form of the Geriatric Depression Scale; Cho et al., 1999) 점수가 정상 범주인 자, (3) 한국판 간이정신상태검사(Korean-Mini Mental State Examination, KMMSE; Kang, 2006)상 연령 및 교육수준에 근거하여 -1 SD를 기준 으로 정상 범주에 속한 자, 4) 한국판 도구적 일상생활기능척도(Korean-Instrumental Activities of Daily Living, K-IADL; Kang et al., 2002)상 점수가.43 이상으로 일상생활기능이 정상 범주에 속한 자, (5) 의사소통 어려움에 대한 주관적 호소를 확인하기 위해 5점 척 도로 제시된 문항('단어를 말할 때 입 밖으로 빨리 단어가 나오지 않는다')에서 '매우 그렇다' 혹은 ‘그렇다'로 응답하여 이름대기 문 제를 호소하고 있는 자로 하였다. 이에 모집된 273명 중, 최종적으 로는 위의 조건에 해당하면서 치료에 동의한 42 명(남 16 명, 여 26 명, 평균연령 $66.64 \pm 6.92$ 세, 교육년수 $12.14 \pm 3.79$ 년, K-MMSE 27.83 \pm 1.76 점)의 대상자에게 한국판 보스톤 이름대기검사(Korean version-Boston Naming Test, K-BNT; Kim \& Na, 1997)를 실시하고 대상자의 연령 및 교육수준에 근거하여 - $1 \mathrm{SD}$ 를 기준으로 K-BNT 정상집단(27명)과 K-BNT 이상집단(15명)으로 분류하였다. 두 집 단의 성별, 연령, 교육년수 및 K-MMSE 점수에 동질성 검정 결과 유 의한 차이가 없었다 $(p>.05)$ (Table 1). 대상자들은 모두 동일한 조 건에서 총 20 회기의 의미자질분석 중재를 받았으며, 중재 전후 2 주 일 내로 인지 및 언어검사를 수행하였다. 본 연구의 모든 절차는 한 림대학교 생명윤리위원회의 승인(HIRB-2016-034)을 받았다.

Table 1. Demographic information of the participants

\begin{tabular}{lccc}
\hline & $\begin{array}{c}\text { Normal group } \\
(\mathrm{N}=27)\end{array}$ & $\begin{array}{c}\text { Abnormal group } \\
(\mathrm{N}=15)\end{array}$ & $p$-value \\
\hline Sex & & & .212 \\
$\quad$ Male & 12 & 4 & \\
$\quad$ Female & 5 & 11 & \\
Age (yr) & $67.22(6.62)$ & $65.60(7.54)$ & .474 \\
Education (yr) & $12.81(3.80)$ & $10.93(3.57)$ & .125 \\
K-MMSE & $28.11(1.67)$ & $27.33(1.87)$ & .174 \\
\hline
\end{tabular}

Values are presented as mean (SD).

K-MMSE = Korean-Mini Mental State Examination. 


\section{중재 도구}

장노년층을 대상으로 한 의사소통 중재교육 프로그램이 전무한 현 시점에서 장노년층에 최적화된 인지 기반 이름대기 중재를 시행 하기 위해서는 해당 연령집단의 의미-어휘목록(semantic-lexical inventories)을 우선적으로 확인하고 이를 바탕으로 한 치료 콘텐 츠가 개발되어야 할 필요가 있다. 그리고 연령에 따른 배경 지식, 사 회문화적 경험과 사용 어휘가 달라지게 되므로 명사 범주 내에서 도 연령대별 인출 요구가 높은 어휘는 다를 수 있다. 또한 성인 중 언 어장애를 경험할 가능성이 있은 연령대가 50-70대인 것을 고려한 다면(Im et al., 2011) 기준 산정을 위한 해당 연령대 정상 성인들의 수행치가 필요하며 치료 자극 선정에 도움이 될 수 있는 각 연령대 에 맞는 기준이 적용된 목록 역시 확보되어야 한다. 이러한 기준에 근거하여 50-70대 정상 성인 401명의 범주별 이름대기의 빈도와 전 형성 평정 연구(Kim, Kang, \& Yoon, 2015)를 통해 구축된 10개의 범주 중 그림으로 구현 시 변별이 어려운 '꽃' 범주를 제외한 9개 범 주에 해당하는 단어들을 선택하였다. 그리고 각 범주 내의 단어를 선행연구의 결과에 따라 3 가지 난이도(고빈도+고전형성, 중빈도+ 중전형성, 저빈도+저전형성)로 나눈 후 직접 중재와 간접 중재 자료 로 사용하였다.

직접 중재를 위한 도구는 선행연구(Boyle, 2004)를 참고하여 워 크북 형태로 제작되었으며, 각 단어는 1 차적으로 미술전공자에 의 해 선화(line drawing)그림으로 구현되고 연구진의 검토를 통해 2 회의 재수정 과정을 거친 후 최종 완성되었다. 워크북 각 장의 중심 에는 그림과 단어를 함께 넣고 그 주위에 빈칸 3 개를 배치하였다. 빈칸의 상단에는 의미자질을 대상자가 직접 분석하는 기회를 제공 하기 위하여 목표단어의 기능, 물리적 속성, 행위, 상위범주 등을 포 함하는 개방형 유도질문을 제시하였다. 가령 목표단어가 '안경'이 라면 개방형 유도질문은 "어떻게 사용하나요(기능)? 어디에 가지고 다니나요(위치)? 어떠한 모양인가요(외형)?”등으로 이루어진다(Appendix 1). 따라서 직접 중재의 단어 선정 시 그림으로 구현 가능하 면서 3 개 이상의 의미자질을 연습하기 쉬운 단어를 선별하였다 또 한 회기당 다양한 범주와 난이도를 포함한 단어를 배정하였다. 이 러한 과정을 거쳐 1-18회기까지는 회기당 새로운 단어 9개씩을 학 습하도록 하였으며(총 162개 단어), 19-20회기에는 이미 사용되었 던 단어들 중 9 개의 범주에 해당하는 1 개씩의 단어를 무작위로 추 출하여 9 개씩 재학습하도록 하였다.

간접 중재의 방법으로는 선행연구로부터 추출된 단어목록 중 그 림으로 구현하기에 다소 힘든 81 개의 단어를 가정 과제로 제시되는 숙제공책 형태로 제작하였다(Appendix 2). 숙제공책은 격자표로 제시된 자질들을 읽고 대상자 스스로 정오 여부를 간단히 '+, -' 형
태로 명기하도록 하였다. 중재프로그램의 처음과 마지막인 1 회기 와 20회기에는 숙제가 없었으며 2-10회기까지 매 회기 9개의 단어 가 숙제로 제시된 후, 반복 차원에서 11-19회기까지 2-10회기와 동 일한 단어를 포함한 과제가 제시되었다. 다수의 언어재활사가 중재 를 시행하는 경우 치료 방법에 대한 개인차가 존재하게 될 가능성 을 배제하기 위하여 언어재활사를 위한 치료매뉴얼을 제작하였으 며, 이를 토대로 전체 연구자 및 보조연구원 워크숍을 진행하였다.

\section{중재 절차}

중재는 공인자격증을 소유한 2급 이상의 언어재활사와 대상자 가 일대일로 대학교 내 언어치료센터나 병원에 별도로 마련된 단독 공간에서 진행되었다. 모든 대상자들은 정해진 스케줄에 따라 주 5 회씩(1회[1시간]/1일) 4 주에 걸쳐 총 20 회기의 의미자질분석 이름대 기 중재를 받았다. 프로그램 실시방법은 SFA와 관련한 선행연구 (Boyle, 2004)를 참조하고 수정하여 총 4단계로 진행되었다. 먼저, 언어재활사는 대상자에게 그림과 단어를 함께 제시하면서 제작된 개방형 유도질문(예: 연필은 어떻게 사용하나요?, 연필은 어떠한 모 양인가요?, 연필은 무엇으로 만들어져 있나요?)을 차례차례 제시하 였다. 대상자는 해당 자질을 구어반응(verbal response)이나 쓰기 반응(written response)으로 응답하도록 하였다. 대상자가 오반응 이나 무반응을 보이는 경우에 언어재활사는 다음과 같은 위계적 단서를 순서대로 제시하였다(질문을 다시 제시-동일범주에 포함되 는 다른 단어를 예시로 사용하여 목표단어의 의미자질을 도출할 수 있도록 제시[예: '연필은 볼펜과 같은 범주에 속합니다']-음절 단 서를 제시-구두로 답을 제시하고 대상자가 따라말하도록 하기). 두 번째 단계로는 대상자가 빈칸을 모두 채운 후에 워트북을 가린 상 태에서 대상자가 해당 자질을 활용하여 목표단어를 문장으로 스 스로 설명하도록 유도하였다(예: '연필은 나무로 만들고 글씨를 쓸 때 사용하고 학교 다닐 때 필통에 넣고 다녔어요'). 세 번째 단계로 는 이전 회기에서 학습한 단어 중 오반응율이 높았던 단어 5 개와 무작위 5 개, 총 10 개씩 추출하여 1단계와 2 단계에서 시행하였던 것 과 동일하게 질문에 대한 해당 자질 분석하기(예: 질문: 연필은 어떻 게 사용하나요?, 답변: 글씨를 쓸 때 사용하고 그림을 그릴 때도 사 용할 수 있어요)와 설명하기(예: '연필은 나무랑 흑연으로 만들어지 고 글씨 쓸 때 사용해요.')를 유도하였다. 단 1 회기와 2 회기에서는 이전 회기에서 학습한 단어의 수가 충분치 않으므로 당일에 학습 한 단어 중 5 개를 임의로 골라 해당단어와 동일 범주에 있는 다른 단어를 산출(예: 연필과 동일한 학용품 범주에 해당되는 단어인 '볼 펜, 지우개, 자, 색연필, 크레파스 등)해 보도록 유도하였다. 마지막 단계에서는 언어재활사가 가정 과제로 제시된 숙제 공책의 시행 여 
부를 확인하고 정오반응을 함께 검토하였다.

\section{사전-사후 검사}

중재효과를 검증하기 위해 사전-사후 비교설계를 사용하였으며, 각각 중재가 시작된 시점과 마감된 시점의 2주일 이내에 사전-사후 검사로 이름대기 및 인지능력 평가를 실시하였다. 먼저 이름대기 능력의 변화를 확인하기 위해 대면이름대기 과제를 실시한 후, 정 반응 점수와 반응시간을 측정하였다. 검사 과제는 K-BNT (Kim \& $\mathrm{Na}, 1997$ )와 중재/비중재 어휘가 동률로 포함된 프로브 검사(probe test)를 제작하여 사용하였다. 프로브 검사는 선행연구(Kim et al., 2015)를 통해 추려진 어휘들 중 그림으로 구현하기 용이하면서 각 범주당 산출빈도 60 위 이내의 고빈도와 중빈도 어휘만을 우선 추 출한 후 다양한 전형성(고-중-저 전형성)이 동률로 구성되도록 하 였다. 보다 객관적이고 질적인 측정을 위하여 두 이름대기검사 모 두 E-prime을 사용하여 제작하고 정반응 여부와 반응시간에 대한 자료를 수집하였다. 그림은 14 인치 노트북 화면에 하나씩 시각적으 로 제시되었으며 대상자는 화면을 응시하면서 제시된 그림에 해당 하는 단어를 노트북에 연결된 마이크(Sony)에 구두로 반응하도록 하였다. 구두 반응 후 검사자가 키보드를 누르면 다음 그림 화면으 로 넘어가도록 제작되었고, 그림이 제시되는 순간부터 키보드를 누 르기까지의 모든 과정은 연결된 마이크를 통하여 하나의 개별적 파 일로 컴퓨터 하드디스크에 녹음되어 저장되었다. E-prime에서 제 공되는 반응시간에 대한 기록은 실제 정반응 여부와는 상관없이 대상자의 음성이 산출되기만 하면 이를 첫 음절로 간주하여 반응 시간을 자동측정하도록 되어 있다. 그러나 대상자들이 때때로 정 반응을 산출하기 전에 간투사나 삽입어 등을 산출하는 경우가 있 었기 때문에 정반응에 대한 반응시간이 부정확하게 측정되는 것을 배제하기 위해 반응시간 산정은 모든 녹음이 끝난 후 저장된 음성 파일을 음성 및 음향분석기기인 Pratt에서 소리파형(wave form)으 로 불러와 그림이 제시된 순간( 0 초로 맞추어져 있음)부터 환자의 실제 정반응의 첫 음절이 시작되기 직전까지의 구간을 $\mathrm{ms}$ 단위로 측정하였다. 반응시간에 대한 분석에서 이상치(outlier)가 평균반 응시간의 평균과 표준편차에 미치는 영향을 줄이기 위하여 반응시 간에 대한 연구(Miller et al., 2006)를 참고하여 $100 \mathrm{~ms}$ 이하의 반응 과 $1,000 \mathrm{~ms}$ 이상의 반응시간은 분석에서 제외하였다. 또한 인지 과제의 반응시간 분석과 관련한 선행연구(Glickman, Gray, \& Morales, 2005)를 참고하여 정반응이 외의 오반응에 대한 반응시간을 분석에 포함할 경우, 과제 해결을 위한 처리과정의 속도뿐만 아니 라 관련 없는 처리과정 소요시간도 포함될 위험이 있다는 근거에 따라 정반응 시간만을 분석하였다.
인지능력과 관련하여, 사전 검사에서는 대상자의 인지 수준을 종합적으로 평가하기 위해 서울신경심리검사 2판(SNSB-II; Kang, Jang, \& Na, 2012)을 시행하였으며, 사후 검사에서는 선별검사로 실 시하였던 K-MMSE를 전반적인 인지능력의 변화를 확인하기 위해 서 다시 실시하였고, SNSB-II에 포함된 검사들 중 이름대기 능력의 영향을 많이 받는 검사인 통제단어연상검사(Controlled Oral Word Association Test, COWAT)의 의미/음소 유창성 과제와 노인용 서 울언어학습검사(Seoul Verbal Learning Test-Elderly's version, SVLT-E)의 즉각회상/지연회상/재인 과제를 실시하였다.

\section{통계분석}

중재에 따른 이름대기 능력의 변화를 확인하기 위해, 반복측정 다변량 분산분석(Multivariate Analysis of Variance)을 통해 집단 (정상, 이상) 및 검사 시기(사전, 사후)에 따른 K-BNT와 프로브 검 사 과제에서의 수행 차이를 분석하였다. 마찬가지로, 인지기능 관 련 검사 과제(예: K-MMSE, COWAT, SVLT-E) 수행결과에 있어 집 단과 검사 시기의 차이가 통계적으로 유의한지 살펴보기 위하여 반복측정 다변량 분산분석을 시행하였다. 주효과에 대한 사후분 석은 Bonferroni 보정 후 시행하였다.

\section{연구결과}

\section{중재에 따른 이름대기 능력의 변화}

분석 결과, K-BNT와프로브 검사의 정반응수와 반응시간에 대한 $\mathrm{K}-\mathrm{BNT}$ 정상집단과 $\mathrm{K}-\mathrm{BNT}$ 이상집단 간 차이가 유의하였고 $\left(F_{(4,37)}=\right.$ $10.570, p<.001)$, 검사 시기의 주효과도 유의하였다 $\left(F_{(4,37)}=18.211\right.$, $p$ <.001). 집단과 검사 시기의 상호작용 효과는 발견되지 않았다 $\left(F_{(4,37)}=.504, p=.733\right)$. 집단의 주효과에 대한 사후분석을 Bonferroni 보정 후 시행한 결과, K-BNT 정상집단이 K-BNT 이상집단보 다 사전과 사후의 K-BNT $(p<.001)$ 와 프로브 검사 $(p=.014)$ 에서 높은 점수를 나타냈으나, 반응시간에서는 두 검사 모두 $(p=.757$; $p=.770)$ 집단 간 차이가 관찰되지 않았다. 측정시기의 주효과에 대 한 사후분석을 Bonferroni 보정 후 시행한 결과, $\mathrm{K}-\mathrm{BNT}(p<.001)$, 프로브 검사 $(p=.01)$ 및 프로브 검사 반응시간 $(p<.001)$ 에서는 사 전에 비하여 사후 검사의 수행력이 개선되었으나 K-BNT 반응시간 $(p=.313)$ 에서는 차이가 없었다. 추가적으로 프로브 검사 비중재 어 휘만의 정반응수와 반응속도를 분석한 결과, 정반응수와 반응시 간 변인에 대한 집단 간 차이가 유의하였고 $\left(F_{(2,39)}=4.069, p=.025\right)$, 측정 시기의 주효과도 유의하였다 $\left(F_{(2,39)}=13.599, p<.001\right)$. 그러나 집단과 측정 시기의 상호작용은 없었다 $\left(F_{(2,39)}=2.603, p=.087\right)$. 이 
Table 2. Descriptive information of pre-post comparisons on the naming tasks for each group

\begin{tabular}{|c|c|c|c|}
\hline & & $\begin{array}{l}\text { Normal group } \\
\qquad(\mathrm{N}=27)\end{array}$ & $\begin{array}{l}\text { Abnormal group } \\
\qquad(\mathrm{N}=15)\end{array}$ \\
\hline \multicolumn{4}{|l|}{ Accuracy } \\
\hline \multirow[t]{2}{*}{ K-BNT (max=60) } & Pre & $49.92(4.47)$ & $39.60(5.51)$ \\
\hline & Post & $53.51(4.00)$ & $44.06(6.18)$ \\
\hline \multirow[t]{2}{*}{ Probe test $(\max =30)$} & Pre & $27.25(2.80)$ & 25.40 (3.04) \\
\hline & Post & $28.14(1.48)$ & $26.40(2.47)$ \\
\hline \multicolumn{4}{|l|}{ Reaction time (sec) } \\
\hline \multirow[t]{2}{*}{ K-BNT } & Pre & $6.17(15.10)$ & $6.21(12.67)$ \\
\hline & Post & $4.55(6.57)$ & $2.94(1.22)$ \\
\hline \multirow[t]{2}{*}{ Probe test } & Pre & $3.01(1.26)$ & $2.80(0.83)$ \\
\hline & Post & $2.17(.76)$ & $2.23(0.39)$ \\
\hline
\end{tabular}

Values are presented as mean (SD).

K-BNT = Korean-Boston Naming Test.

에 집단의 주효과에 대한 사후분석을 Bonferroni correction 보정 후 실시한 결과, 집단 간 정반응수에서는 차이가 있었으나 $(p=.031)$, $\mathrm{RT}$ 에서는 차이가 없었다 $(p=.370)$. 측정 시기의 주효과에 대한 사 후분석을 Bonferroni correction 보정 후 실시한 결과, 정반응수 $(p<.001)$ 와 RT $(p=.005)$ 는 사전과 사후 간에 유의한 차이가 있었 다. 이름대기 검사 및 검사 측정 시기에 따른 집단별 정반응수와 반 응시간은 Table 2에 제시하였다.

\section{중재에 따른 인지 능력의 변화}

분석 결과, 하위 검사 수행력에 대한 집단 간 차이는 없었으나 $\left(F_{(6,35)}=1.075, p=.396\right)$, 검사 시기의 주효과는 유의하였다 $\left(F_{(6,35)}=\right.$ $420.818, p<.001)$. 집단과 검사 시기의 상호작용효과는 발견되지 않았다 $\left(F_{(6,35)}=1.023, p=.427\right)$. 이에 검사 시기의 주효과에 대한 사 후분석을 Bonferroni 보정 후 시행한 결과, COWAT의 음소유창성 $(p=.048)$, SVLT-E의 즉각회상 $(p<.001)$ 및 지연회상 $(p<.001)$ 과제 의 사후 검사에서 수행력이 유의하게 증가되었고, K-MMSE, COWAT의 의미유창성, SVLT-E의 재인과제에서는 사전과 사후의 차 이가 유의하지 않았다 $(p=.094 ; p=.990 ; p=.853)$. 인지기능검사 및 검사측정 시기에 따른 집단별 수행력은 Table 3에 제시하였다.

\section{논의 및 결론}

대면이름대기의 처리과정을 설명하는 다양한 모델이 있지만 동 일하게 포함되는 과정에는 다음의 단계들이 포함된다. 우선, 제시 되는 자극을 시각적 분석을 통해 인식한 후, 의미적 표상(semantic representation)에 접근하고 음운적 어휘표상(phonological-lexical
Table 3. Descriptive information of pre-post comparisons on the cognitive tests for each group

\begin{tabular}{llcc}
\hline & & $\begin{array}{c}\text { Normal group } \\
(\mathrm{N}=27)\end{array}$ & $\begin{array}{c}\text { Abnormal group } \\
(\mathrm{N}=15)\end{array}$ \\
\hline K-MMSE & Pre & $28.11(1.67)$ & $27.33(1.87)$ \\
& Post & $28.40(1.50)$ & $28.06(2.01)$ \\
COWAT & & & \\
Semantic fluency & Pre & $33.33(7.60)$ & $28.86(8.30)$ \\
(animal+supermarket) & Post & $34.29(9.67)$ & $27.93(10.46)$ \\
Phonemic fluency ( $\neg+$ +^) $)$ & Pre & $25.96(7.93)$ & $20.73(9.20)$ \\
& Post & $28.77(8.78)$ & $22.33(10.25)$ \\
SVLT-E & & & \\
Immediate recall & Pre & $20.22(4.78)$ & $18.46(4.51)$ \\
& Post & $23.81(5.24)$ & $21.33(5.00)$ \\
Delayed recall & Pre & $6.40(2.45)$ & $5.40(2.82)$ \\
& Post & $7.96(2.98)$ & $6.93(2.28)$ \\
Recognition & Pre & $21.00(2.11)$ & $20.46(2.23)$ \\
& Post & $21.70(2.38)$ & $19.93(2.93)$ \\
\hline
\end{tabular}

Values are presented as mean (SD).

K-MMSE= Korean-Mini Mental State Examination; COWAT = Controlled Oral Word Association Test; SVLT-E=Seoul Verbal Learning Test-Elderly's version.

representation)과의 연결 단계를 거쳐 구두 표현을 위한 운동 프로 그램으로 변환되는 것이다. 노화과정에서 이름대기의 어려움을 경 험하게 되는 다양한 이유 중 하나로 전달손실가설(transmission deficit hypothesis)이 자주 언급되는데, 이는 단어를 산출할 때 의 미마디(semantic node)와 음운마디(phonological node)의 활성이 불충분하게 일어나거나, 의미정보는 활성화되었지만, 음운정보는 충분히 점화되지 않아 어휘 인출의 어려움을 보이는 것을 말한다 (Burke et al., 1991). 장노년층의 경우, 위의 단계 중 음운적 어휘표 상 단계에서 노화의 영향을 받아 이름대기의 어려움을 보일 수 있 으며(Shafto, Burke, Stamatakis, Tam, \& Tyler, 2007), 감소된 작업 기억과 주의력은 이름대기의 어려움을 더욱 가속화하는 것으로 알 려져 있다(Cohen \& Burke, 1993). 따라서 본 연구는 노화과정에서 빈번히 이름대기의 어려움을 호소하는 장노년층을 대상으로 이름 대기 검사의 수행력에 따라 두 집단(정상, 이상)으로 나눈 후 개별 SFA 중재프로그램을 적용해 봄으로써 대면이름대기 및 언어유창 성, 언어기억 검사 수행력에서의 개선효과와 집단 간 중재효과의 차이를 살펴보았다. 이를 통해, 목표어와 관련된 의미자질을 산출 하게 하여 연관 의미자질로 접근하는 전략의 사용을 자동화시키 는 SFA 전략이 노화과정에서 관찰되는 이름대기의 어려움을 해결 해주는지, 그리고 궁극적으로는 치매의 예방차원에서 이 중재방법 을 적극 활용할 수 있는지 임상적 근거를 검증해 보고자 하였다.

먼저 사전-사후로 이름대기 과제 수행력의 비교를 통한 중재효 
과성 측면에서, 비중재어휘로만 구성된 표준화 검사(K-BNT)와 중 재/비중재 어휘로 구성된 비표준화 검사(프로브 검사) 모두에서 K$\mathrm{BNT}$ 정상집단과 K-BNT 이상집단의 정반응수가 증가하였다. 이는 $\mathrm{SFA}$ 의 기본원리가 다각적으로 의미체계를 자극하여 전반적인 네 트워크를 활성화하고 목표단어가 산출될 수 있는 역치를 증가시키 는 것이므로, 20 회기에 걸친 SFA 중재과정을 통해 노화 과정에서 약화된 마디 연결이 향상되고, 점화가 효율적으로 확산된 것으로 해석해볼 수 있다. 단어를 인출하기 위한 단계에서 의미정보와 음 운정보의 연결은 고빈도 단어일수록, 그리고 최근에 사용한 단어 일수록 강화되는데(Burda, 2011) 실제, 중재 과정에서 많은 피험자 들은 '이 단어를 최근에 말할 일이 없었는데, 다시 생각해 보고 말 로 자꾸 표현하다보니, 쉬워지고 입에 붙고 좋다.'라는 의견을 보이 는 등 SFA 중재의 마디 간 강화효과를 확인할 수 있었다. K-BNT 정 상집단과 K-BNT 이상집단 간의 정반응수의 차이는 중재 후에도 유지되었으나 두 집단 모두의 정반응수가 중재 후 증가하였고 반응 시간 측면에서는 K-BNT 정상집단과 K-BNT 이상집단 모두 사후 프로브 검사의 반응시간이 단축되었다. 프로브 검사에는 중재어휘 와 비중재 어휘가 섞여 있어, 사실상 중재 후 프로브 검사에서 발견 된 정반응수의 증가와 반응속도의 감소가 중재어휘에서만 관찰될 수 있는 학습효과 때문인지, 혹은 비중재 어휘에도 일반화효과가 관찰된 것인지를 확인할 필요가 있었다. 따라서 비중재 어휘만을 대상으로 추가 분석을 실시한 결과, K-BNT 정상집단과 이상집단 모두 비중재 어휘에서도 중재 후 정반응수가 증가하고 반응속도가 감소되는 양상이 관찰되었다. 이러한 결과는 SFA를 통해서 네트워 크의 활성화가 효과적으로 개선되었음을 의미하는 것이다. 그간 $\mathrm{SFA}$ 의 중재효과를 살펴본 연구들은 대부분 소수의 실어증 환자를 대상으로 진행되어 왔으므로(Edmonds, Nadeau, \& Kiran, 2009; Wambaugh \& Ferguson, 2007) 본 연구결과를 기존의 연구결과들 과 직접적으로 비교하기는 어렵다. 그러나 노화과정 또한 신경생리 적 변화로 인한 관련 기능의 감소 및 부전이므로 질환으로 인한 장 애의 연장선상에서 이를 비교해 보고자 한다. 실어증 환자를 대상 으로 한 기존의 연구에서는 표준화 검사와 더불어 중재 어휘와 비 중재 어휘를 모두 평가하였으나 특히 비중재 어휘에 대한 효과가 유 효하거나(Harnish et al., 2014) 유효하지 않아서(Rider et al., 2008; Wambaugh \& Ferguson, 2007) 서로 상이한 결과들이 보고되었다 (Kiran, 2008). 이에 실어증 환자를 대상으로 시행된 SFA 중재효과 에 대한 메타분석 결과(Oh, Eom, Park, \& Sung, 2016)는 중재 어휘 에서는 효과 크기가 높았으나 비중재 어휘에서는 낮은 효과크기를 보여, BNT와 같은 표준화 이름대기 검사에서는 효과가 없다고 보 고하였다. 퇴행성 질환에서는 초기(Mo et al., 2015)와 중도-중등도
알츠하이머병(Alzheimer's disease) 치매(Kang et al., 2015)환자 각 6명씩을 대상으로 한 연구에서 지필형태나 컴퓨터 중재프로그램 형태의 SFA를 적용하였을 때, 비중재 단어로의 일반화효과가 유의 하지 않았음이 관찰되었다. 중재 어휘의 경우에는 반복 경험으로 인하여 네트워크가 형성될 수 있지만 비중재 어휘는 반복 경험에 의한 네트워크만으로는 산출하기가 어려울 수 있다. 즉, 형성된 네 트워크를 바탕으로 유사범주 내에서 혹은 전혀 다른 범주로의 가지 뻗기가 이루어져야 비로소 산출할 수 있는 것이다. 상기 언급한 연 구들은 대부분 뇌손상이 명백한 뇌졸중이나 치매 환자를 대상으 로 하였으므로 네트워크 자체의 손상으로 인해 활성화에 제한이 있을 수 있고, 결국 SFA와 같은 간접적인 활성화가 비중재 어휘에 는 크게 영향을 주지 못하였을 가능성이 있다. 그러나 본 연구의 대 상자들은 뇌손상이 없고 전반적인 인지기능이 유지되는 장노년층 에 해당하였으므로 이러한 간접 활성화만으로도 비중재 어휘를 산출할 수 있는 가지뻗기가 가능했던 것으로 해석된다.

보다 흥미로운 결과는 K-BNT 정상집단과 K-BNT 이상집단 모 두 사전에 비해 사후의 이름대기 능력이 개선되었고 중재 전 어휘 인출의 어려움 정도와 상관없이 이름대기 중재의 효과가 동일하였 다는 점이다. 이러한 결과는 뇌의 비축 역량과 관련지어 설명해 볼 수 있다. 인지적 비축 능력은 개인차가 크고 광범위하여 노화의 영 향을 받더라도 이로 인한 손실 정도와 양상은 서로 다를 수 있다 (Satz, 1993). 또한 비축 능력은 제한된 인지적 자원이 있는 상태에 서는 오류를 발생시키지 않도록 전략적으로 작동하고(Bennett, Arnold, Valenzuela, Brayne, \& Schneider, 2014) 본인이 가진 역량 을 활용하여 주어진 성과를 최적화하거나 최대화시킬 수 있도록 한다(Kliegl, Smith, \& Baltes, 1989). 이러한 맥락에서 본 연구에 포 함된 K-BNT 이상집단 15 명의 대상자는 비록 K-BNT라는 객관적 검사상에서는 이름대기 장애로 판정되어 이상집단에 속하였을지 라도 전반적인 인지능력을 반영하는 K-MMSE의 평균점수가 높고 (사전 27점, 사후 28점) 모두 정상 범주에 속하였으며, 도구적 일상 생활능력(K-IADL) 검사를 통해 일상생활 기능이 유지되고 있는 것으로 확인된 장노년층이었으므로 제한된 비축 능력을 전략적으 로 활용하였을 수 있다. 더불어 객관적 검사상으로는 K-BNT 정상 집단에 속한 27 명의 대상자는 유지된 비축 능력을 최대치로 활용 할 수 있었기 때문에 사전 이름대기검사의 점수가 높았음에도 불 구하고 중재효과가 관찰되었을 가능성이 있다. 흥미롭게도 K-BNT 정상집단에 속한 대상자들의 종합적인 신경심리검사(SNSB-II) 프 로파일을 살펴본 결과, 27 명 중 정상 범주로 분류된 대상자는 단 2 명이었고, 나머지 25 명은 모두 1 개 이상의 인지기능이 정상 범주 이 하로 저하된 경도인지장애(MCI)에 해당하였다. 따라서 본 연구의 
기본 설계가 이름대기 능력에 따라 두 집단으로 구분하여 중재효 과를 비교하였지만, 실제적으로 $\mathrm{MCI}$ 가 대부분을 차지하고 있었으 므로, 집단 구분에 상관없이 이름대기 중재의 긍정적 효과가 있었 음을 보여준다.

추가적으로 분석한 COWAT의 음소유창성과 SVLT-E의 즉각 및 지연회상 과제에서도 K-BNT 정상집단과 K-BNT 이상집단 모두 중 재 후 수행력 향상이 관찰되었다. COWAT은 정보인출 과정을 통제 하는 전두엽 기능과 관련이 있으며, 대면이름대기와 더불어 이름대 기능력을 확인하는 대표 지표로 사용된다(Sorond, Schnyer, Serrador, Milberg, \& Lipsitz, 2008). 따라서 SFA 중재 후 COWAT 과제 에서의 수행력이 유의하게 향상된 것은 4주간에 걸친 이름대기와 관련된 활성화가 다각적 점화를 통해 전두엽의 활동성도 증가시키 면서 결과적으로는 어휘인출 능력을 개선시키는 긍정적 효과를 가 져온 것으로 해석해 볼 수 있다. 장노년층의 COWAT 수행력이 향상 된 또 다른 이유로 COWAT 과제의 특성을 들 수 있는데, 생성이름 대기로도 불리우는 COWAT은 정해진 시간 내에 주어진 범주에 속 하는 단어를 가능한 많이 산출해야 하기 때문에 원활한 수행을 위 해 군집화와 전환 전략이 요구된다(Frith, Friston, Liddle, \& Frackowiak, 1991; Klein, Milner, Zatorre, Meyer, \& Evans, 1995). 군집화 란 제시된 범주 내에서 서로 연관된 어휘들을 전략적으로 모아 산 출하는 것이며 전환은 하위 범주의 단어를 모두 인출하고 난 후에 또 다른 하위 범주로 이동하는 것을 말하며 고갈된 정보를 대체하 는 유연한 사고능력을 반영한다(Troyer, Moscovitch, Winocur, Alexander, \& Stuss, 1998). 군집화를 잘 하기 위해서는 동일 범주 안 에 속한 목록 간의 유사점을 잘 파악할 수 있어야 하고, 전환을 잘 하기 위해서는 동일 범주 안에 속하지만 그 하위 범주 간의 차이점 을 찾아내어 변별을 할 수 있는 능력이 필요하다. SFA는 목표단어 가 속한 상위 범주, 용도, 물리적 속성, 행위 등을 분석하면서 동일 한 범주에 속한 다른 항목들과 어떻게 구별되는지, 서로 유사한 점 은 무엇인지를 사고하게 하여 목표단어에 더 주요한 자질들을 산출 하도록 유도한다. 이러한 과정을 통하여 대상자들은 어휘목록 간 의 관계를 활성화시키고 견고히 하게 되면서 같은 범주 내의 유사 한 자질과 유사하지 않은 자질을 분리하는 능력을 키울 수 있을 것 이다. 따라서 본 연구대상자들이 SFA 중재를 통해 제시된 범주 내 에서 관련이 있거나 관련되지 않은 어휘목록을 유기적으로 연결하 는 연습을 반복함으로써 목표단어로 접근하는 전략의 사용이 더 욱자동화되었을 가능성이 있다고 볼수 있다.

마지막으로, 단어목록으로 구성된 SVLT-E에서 즉각 및 지연회 상 과제에서는 중재 후 유의한 향상이 관찰되었으나 재인 과제에서 는 그 효과를 관찰할 수 없었다. SVLT-E는 새로운 언어 정보의 학
습과 유지 정도의 양을 측정하여 언어적 기억과 개념적 능력 사이 의 상호작용을 평가할 수 있는 과제로서(Choi, 2007), 일반적으로 언어학습검사의 수행에는 기억력뿐만 아니라 이름대기능력이 유 의한 영향을 미치는 것으로 알려져 있다(Melrose et al., 2009). 그러 나 기억의 각 단계별 양상을 확인하기 위한 검사이므로 하위 과제 에 따라수행 시 요구되는 기능에서 다소 차이가 있다. 즉각 및 지연 회상 과제의 경우에는 대상자가 어휘목록을 구두로 인출해야 하지 만 재인 과제에서는 직접적인 어휘 인출이 요구되지 않는다. 따라서 이름대기에 기반한 SFA 중재의 효과가 SVLT-E의 하위 과제 내에 서도 어휘의 인출능력이 필요한 즉각 및 지연회상 과제에 더 반영 되었을 가능성이 있다. 추가적으로는 사전 검사 시기에서의 재인 과제 수행력이 높았으므로 천장 효과로 인해 사후 검사 점수에서 의 상승이 없었을 가능성도 있다. 특히 기억력 저하는 추후 치매로 의 진행을 예측하는 강력한 변인(Jonker, Launer, Hooijer, \& Lindeboom, 1996; Schmand, Jonker, Hooijer, \& Lindeboom, 1996)임을 고려해 본다면 이에 대한 조기 중재적 개입은 매우 중요한 부분이 다. 그러나 본 연구결과만으로는 의미자질분석과 같은 네트워크 활 성화에 중점을 두는 치료 접근법이 이름대기 능력을 넘어서 실제 로 전두엽의 통제능력 혹은 언어적 기억력을 촉진시킨다고 단정할 수는 없으므로 추가 연구를 통해 근거기반실제(evidence-based practice)를 구축할 필요가 있다.

본 연구의 제한점은 다음과 같다. 먼저, 이름대기검사와 인지기 검사에서 관찰된 통계적으로 유의한 수준의 개선을 SFA 중재의 직 접적인 결과물로서 결론을 내리는 것에는 주의가 필요하다. 대상자 들은 프로브 검사에서 중재 후 평균점수 1 점 정도의 향상을 보였으 며, K-BNT에서는 사후 4점 정도의 향상이 있었으나 이는 프로브 검사항목수와 비교하여 2 배수의 항목으로 저빈도 단어가 더 많이 포함된 것이 점수 향상에 영향을 주었을 가능성이 있다. 연구 설계 측면에서의 제한점으로는, SFA 중재의 일반화효과를 확인하기 위 하여 중재어휘 외에도 비중재 어휘를 혼합한 프로브 검사를 사전사후로 평가하였지만 실제 60 개 항목이면서 고, 중, 저빈도가 골고 루 섞인 K-BNT와 달리 프로브 검사의 경우 시각적 그림 구현의 여 부와 전형성을 고려하면서 구성하다 보니 K-BNT보다 적은 30개 항목이면서, 고빈도와 중빈도 위주로 포함되어 두 검사의 난이도가 동일하지 못했다는 점이다. 따라서 비중재어휘로 구성된 표준화 검 사와 중재 및 비중재 어휘로 구성된 비표준화 검사상에서의 사전사후 중재효과를 맞비교하여 일반화효과를 논의하기에는 논리적 근거가 미약하다는 점을 들 수 있다. 유사한 맥락에서 중재와 효과 의 인과관계를 보다 명확히 하기 위해서는 통제 집단을 포함한 무 작위통제연구의 필요성이 제시된다. 또한 이름대기 능력을 가장 타 
당하게 평가할 수 있는 방법으로 반응시간과 정반응 점수를 산정 하였지만, 이 두 요소가 모든 인지-언어처리과정을 설명해 줄 수 없 으며, 어휘 처리를 수행하면서 동반되는 다른 처리과정들을 배제하 고 본질적인 특성만 볼 수도 없기 때문에 인지-언어처리과정 연구 에서 뒤따르는 본질적인 한계점을 안고 있다. 따라서 중재의 보다 직접적인 근거를 제시하기 위해서는 뇌영상기법 분석을 활용하여 $\mathrm{SFA}$ 중재 전후 장노년층의 행동 수행력 변화와 뇌의 활성화 양상 간의 관계를 확인하는 후속연구가 이루어져야 할 것이다. 이를 통 해 대상자가 가진 기능적 저하에 대항하여 뇌의 인지적 자원을 활 용하는 방식과 인지적 퇴행을 완화시키는 뇌가소성의 메커니즘이 무엇인지를 규명할 수 있을 것이다. 마지막으로, 실험 자극어 선정 과정에서 뇌손상 환자의 치료목적으로 적용하는 방법과 동일하게 어휘 친숙도, 빈도, 전형성 등을 고려하였으나, 실제 중재 과정에서 본 연구대상자들은 친숙하지만 저빈도 단어일수록 좀 더 여러가지 자질을 생각하게 되고 자극이 된다고 보고하기도 하였다. 또한 자 질을 자유로이 떠올려서 적거나 말해보는 수준 이상의 활동(예: 백 과사전이나 온라인 웹사이트 검색을 통해 좀 더 어려운 사실적 정 보를 학습하거나 떠올려보고 싶어 함)을 요구하기도 하였다. 이는 중재방법의 기저에 있는 이론은 동일할지라도 대상자의 현재 상태 와 수준에 따라 적용할 수 있는 어휘 목록과 접근 방식이 다각화되 어야함을 시사하는 것이다.

이러한 제한점에도 불구하고 본 연구는 임상적 적용의 측면에서 중요한 시사점을 가진다. 일반적으로 정상 노인에서 1-2\% 정도가 치매로 진행하는 것과 비교하여 $\mathrm{MCI}$ 의 경우 1 년에 대략 $12 \%$ 의 환 자들이 치매로 진행한다(Petersen, 2004). 특히 손상된 인지 영역이 둘 이상인 다영역 기억성 경도인지장애는 알츠하이머형 치매로 진 행될 확률이 높은 것으로 알려져 있는데(Petersen, 2004), 본 연구 에 포함된 42 명 중 23 명 $(54 \%)$ 이 이에 해당하였다. 본 연구에 참여한 대상자들은 스스로 이름대기 능력이 저하되었다고 느끼고 있지만 이를 주소로 병원에 내원한 적이 없고 지역사회에서 일상생활을 잘 영위하고 있는 사람들이었다. 그러나 종합적인 신경심리검사 결과 에 의하면 이들 중 단 2 명(4.7\%)을 제외하고 모두가 $\mathrm{MCI}$ 범주에 속 하며 특히 $54 \%$ 가 치매의 고위험군에 속하는 것으로 밝혀졌다. 이 처럼 지역사회의 장노년층이 임상적 검사로 의뢰되지 않고 여전히 지역사회보건 사각지대에서 치매 고위험군으로 남겨져 있다는 사 실은 매우 우려되는 일이다.

본래 SFA 중재는 외상성 뇌손상 환자들의 인지나 의사소통 장 애를 치료하기 위해 제안된 것으로(Haarbauer-Krupa et al., 1985) 의미체계 손상과 관련된 가장 대표적인 언어중재 방법이다. 이 방 법은 명사의 의미자질을 계속해서 비교하고 대조하게 함으로써 의
미자질을 강화하고 의미네트워크를 활성화시킬 뿐만 아니라, 담화 수준에서의 어휘의미처리 능력(DeLong, Nessler, Wright, \& Wambaugh, 2015)과, 전반적인 의사소통능력(Haarbauer-Krupa et al., 1985)의 향상에도 기여하는 것으로 알려져 있어 기본적으로 의미 체계가 손상되어 있는 실어증 환자나 DAT 환자의 구어산출 향상 을 위해 주로 사용되어 왔다. $\mathrm{MCI}$ 의 경우에는 초기부터 말기에 이 르기까지 뇌손상의 유무와 정도 및 관찰되는 양상이 매우 이질적 이므로 이러한 중재가 예방의 효과로 적용되는 대상자도 있지만, 조기 중재의 목적으로 적용가능한 대상자도 있을 것이다. 퇴행성 질환을 갖고 있는 노인들의 경우 점진적으로 진행하는 양상을 주 특징으로 하고, 전반적인 언어와 인지능력도 지속적으로 저하되는 특성을 보이기 때문에 언어중재에 대한 필요성이 다른 신경언어장 애군에 비해 부각되지 않는 편이다. 한 국내연구(Mo et al., 2015)에 서도 퇴행성 환자에 대한 언어중재는 제고할 필요가 있음을 언급 하기도 하였다. 따라서 언어병리학 분야에서 시행되는 언어중재는 좀 더 이른 시기에 예방 및 조기 중재의 목적을 갖고 개입하는 것이 고무적일 것으로 사료된다. 그런 의미에서 전반적 의사소통능력 향 상에 목표를 두고 있는 SFA를 그간 중재의 필요성이 대두되지 않 았던 주관적 기억장애나 초기 경도인지장애 환자에게 적용해 봄으 로써 그 가능성과 일반화효과를 예비적으로 확인한 본 연구결과 는 병리적 노화로의 진입을 예방하는 차원에서 SFA의 보다 광범위 한 적용 근거를 제공해 준다고 볼 수 있다.

\section{REFERENCES}

Barnes, D. E., Yaffe, K., Belfor, N., Jagust, W. J., DeCarli, C., Reed, B. R., \& Kramer, J. H. (2009). Computer-based cognitive training for mild cognitive impairment: results from a pilot randomized, controlled trial. Alzheimer Disease and Associated Disorders, 23(3), 205-210.

Barresi, B. A., Nicholas, M., Tabor Connor, L., Obler, L. K., \& Albert, M. L. (2000). Semantic degradation and lexical access in age-related naming failures. Aging, Neuropsychology, and Cognition, 7(3), 169-178.

Belleville, S., Gilbert, B., Fontaine, F., Gagnon, L., Ménard, É., \& Gauthier, S. (2006). Improvement of episodic memory in persons with mild cognitive impairment and healthy older adults: evidence from a cognitive intervention program. Dementia and Geriatric Cognitive Disorders, 22(5-6), 486499.

Bennett, D. A., Arnold, S. E., Valenzuela, M. J., Brayne, C., \& Schneider, J. A. (2014). Cognitive and social lifestyle: links with neuropathology and cognition in late life. Acta Neuropathologica, 127(1), 137-150. 
Bowles, N. L., \& Poon, L. W. (1985). Aging and retrieval of words in semantic memory. Journal of Gerontology, 40(1), 71-77.

Boyle, M. (2004). Semantic feature analysis treatment for anomia in two fluent aphasia syndromes. American Journal of Speech-Language Pathology, 13(3), 236-249.

Boyle, M., \& Coelho, C. A. (1995). Application of semantic feature analysis as a treatment for aphasic dysnomia. American Journal of Speech-Language Pathology, 4(4), 94-98.

Buckner, R. L., Head, D., \& Lustig, C. (2006). Brain changes in aging: a lifespan perspective. In E. Bialystok \& F. I. M. Craik (Eds.), Lifespan cognition: mechanisms of change (pp. 27-42). New York, NY: Oxford University Press.

Burda, A. N. (2011). Communication and swallowing changes in healthy aging adults. Sudbury, MA: Jones \& Bartlett Learning.

Burke, D. M., MacKay, D. G., Worthley, J. S., \& Wade, E. (1991). On the tip of the tongue: what causes word finding failures in young and older adults? Journal of Memory and Language, 30(5), 542-579.

Carretti, B., Borella, E., Fostinelli, S., \& Zavagnin, M. (2013). Benefits of training working memory in amnestic mild cognitive impairment: specific and transfer effects. International Psychogeriatrics, 25(4), 617-626.

Choi, J. (2007). Elderly memory disorder scale. Seoul: Hakjisa.

Cho, M. J., Bae, J. N., Suh, G. H., Hahm, B. J., Kim, J. K., Lee, D. W., \& Kang, M. H. (1999). Validation of geriatric depression scale, Korean version (GDS) in the assessment of DSM-III-R major depression. Journal of Korean Neuropsychiatric Association, 38(1), 48-63.

Christensen, K. J., Multhaup, K. S., Nordstrom, S., \& Voss, K. (1991). A cognitive battery for dementia: development and measurement characteristics. Psychological Assessment, 3(2), 168-174.

Coelho, C. A., McHugh, R. E., \& Boyle, M. (2000). Semantic feature analysis as a treatment for aphasic dysnomia: a replication. Aphasiology, 14(2), 133142.

Cohen, G., \& Burke, D. M. (1993). Memory for proper names: a review. Memory, 1(4), 249-263.

Cohen, G., \& Faulkner, D. (1986). Memory for proper names: age differences in retrieval. British Journal of Developmental Psychology, 4(2), 187-197.

Collins, A. M., \& Loftus, E. F. (1975). A spreading-activation theory of semantic processing. Psychological Review, 82(6), 407-428.

Conley, A., \& Coelho, C. (2003). Treatment of word retrieval impairment in chronic Broca’s aphasia. Aphasiology, 17(3), 203-211.

DeLong, C., Nessler, C., Wright, S., \& Wambaugh, J. (2015). Semantic feature analysis: Further examination of outcomes. American Journal of Speech-
Language Pathology, 24(4), S864-S879.

Edmonds, L. A., Nadeau, S. E., \& Kiran, S. (2009). Effect of Verb Network Strengthening Treatment (VNeST) on lexical retrieval of content words in sentences in persons with aphasia. Aphasiology, 23(3), 402-424.

Frith, C. D., Friston, K. J., Liddle, P. F., \& Frackowiak, R. S. J. (1991). A PET study of word finding. Neuropsychologia, 29(12), 1137-1148.

Galante, E., Venturini, G., \& Fiaccadori, C. (2007). Computer-based cognitive intervention for dementia: preliminary results of a randomized clinical trial. Giornale Italiano di Medicina del Lavoro ed Ergonomia, 29(3 Suppl B), B26-32.

Glickman, M. E., Gray, J. R., \& Morales, C. J. (2005). Combining speed and accuracy to assess error-free cognitive processes. Psychometrika, 70(3), 405-425.

Haarbauer-Krupa, J., Moser, L., Smith, G., Sullivan, D. M., Szekeres, S. F., \& Ylvisaker, M. (1985). Cognitive rehabilitation therapy: middle stages of recovery. In M. Ylvisaker (Ed.), Head injury rehabilitation: children and adolescents (pp. 287-310). San Diego, CA: College-Hill Press.

Harnish, S. M., Morgan, J., Lundine, J. P., Bauer, A., Singletary, F., Benjamin, M. L., ... \& Crosson, B. (2014). Dosing of a cued picture-naming treatment for anomia. American Journal of Speech-Language Pathology, 23(2), S285S299.

Heine, M. K., Ober, B. A., \& Shenaut, G. K. (1999). Naturally occurring and experimentally induced tip-of-the-tongue experiences in three adult age groups. Psychology and Aging, 14(3), 445-457.

Im, J. H., Lee, K. S., Kim, K. Y., Hong, N. S., Lee, S. W., \& Bae, H. J. (2011). Follow-up study on mortality in Korean stroke patients. Journal of the Korean Medical Association, 54(11), 1199-1208.

Jang, J. S., Lee, J. S., Kim, S. K., \& Jeon, B. J. (2012). The change in spaced retrieval training (SRT) Combined with errorless learning on cognitive function and depression in dementia sufferers. Journal of Korean Society of Occupational Therapy, 20(4), 43-55.

Jonker, C., Launer, L. J., Hooijer, C., \& Lindeboom, J. (1996). Memory complaints and memory impairment in older individuals. Journal of the American Geriatrics Society, 44(1), 44-49.

Kang, J. Y., Sung, J. E., \& Lee, S. E. (2015). Effects of computerized language intervention on abilities of time-person-place orientation and naming for individuals with dementia of the Alzheimer's type. Communication Sciences \& Disorders, 20(2), 237-254.

Kang, S. J., Choi, S. H., Lee, B. H., Kwon, J. C., Na, D. L., \& Han, S. H. (2002). The reliability and validity of the Korean Instrumental Activities of Daily 
Living (K-IADL). Journal of the Korean Neurological Association, 20(1), 8-14.

Kang, Y. (2006). A normative study of the Korean-Mini Mental State Examination (K-MMSE) in the elderly. Korean Journal of Psychology: General, 25(2), 1-12.

Kang, Y., Jang, S. M., \& Na, D. L (2012). Seoul Neuropsychological Screening Battery (2nd ed.). Seoul: Human Brain Research \& Consulting.

Kim, H. (2012). Neurologic speech-language disorders. Seoul: Sigmapress.

Kim, H., \& Na, D. L. (1997). Korean Boston Naming Test (K-BNT). Seoul: Hakjisa.

Kim, J., Kang, Y., \& Yoon, J. H. (2015). Category norms for Korean adults age 55 to 74. Communication Sciences \& Disorders, 20(4), 559-569.

Kim, J. W., Hwang, J. H., Kim, S. R., \& Kim, H. (2013). Differences in attention and naming ability with age in the elderly. Journal of Speech \& Hearing Disorders, 22(3), 25-44.

Kim, S. J., \& Choi, H. (2012). Characteristics of verbal definitions in normal elderly Koreans. Korean Journal of Communication \& Disorders, 17(1), 107117.

Kiran, S. (2008). Typicality of inanimate category exemplars in aphasia treatment: further evidence for semantic complexity. Journal of Speech, Language, and Hearing Research, 51(6), 1550-1568.

Kiran, S., \& Thompson, C. K. (2003). The role of semantic complexity in treatment of naming deficits: training semantic categories in fluent aphasia by controlling exemplar typicality. Journal of Speech, Language, and Hearing Research, 46(4), 773-787.

Klein, D., Milner, B., Zatorre, R. J., Meyer, E., \& Evans, A. C. (1995). The neural substrates underlying word generation: a bilingual functional-imaging study. Proceedings of the National Academy of Sciences, 92(7), 2899-2903.

Kliegl, R., Smith, J., \& Baltes, P. B. (1989). Testing-the-limits and the study of adult age differences in cognitive plasticity of a mnemonic skill. Developmental Psychology, 25(2), 247-256.

Law, S. P., Wong, W., Sung, F., \& Hon, J. (2006). A study of semantic treatment of three Chinese anomic patients. Neuropsychological Rehabilitation, 16(6), 601-629.

Lee, N. R., \& Kim, S. J. (2013). The effect of instrumental activities of daily living (IADL) on memory training in mild cognitive impairment. Journal of Korean Society of Cognitive Rehabilitation, 2(1), 5-19.

Lovelace, E. A., \& Twohig, P. T. (1990). Healthy older adults' perceptions of their memory functioning and use of mnemonics. Bulletin of the Psychonomic Society, 28(2), 115-118.

Melrose, R. J., Campa, O. M., Harwood, D. G., Osato, S., Mandelkern, M. A.,
\& Sultzer, D. L. (2009). The neural correlates of naming and fluency deficits in Alzheimer's disease: an FDG-PET study. International Journal of Geriatric Psychiatry, 24(8), 885-893.

Miller, C. A., Leonard, L. B., Kail, R. V., Zhang, X., Tomblin, J. B., \& Francis, D. J. (2006). Response time in 14-year-olds with language impairment. Journal of Speech, Language, and Hearing Research, 49(4), 712-728.

Ministry of the Interior and Safety. (2017). Elderly population Statistics. Seoul: Author.

Mo, K. O., Sung, J. E., \& Jeong, J. H. (2015). The effects of semantic feature analysis treatment on naming performance in Korean individuals with early dementia of the Alzheimer's type: using a familiarity of nouns scale. Communication Sciences \& Disorders, 20(1), 34-47.

Mortensen, L., Meyer, A. S., \& Humphreys, G. W. (2006). Age-related effects on speech production: a review. Language and Cognitive Processes, 21(13), 238-290.

Mun, H. S. (2001). Literacy and cognitive function in the Korean elderly subjects (Master's thesis). Sungshin Women's University, Seoul, Korea.

Oh, S. J., Eom, B., Park, C., \& Sung, J. E. (2016). Treatment efficacy of semantic feature analyses for persons with aphasia: evidence from meta-analyses. Communication Sciences \& Disorders, 21(2), 310-323.

Petersen, R. C. (2004). Mild cognitive impairment as a diagnostic entity. Journal of Internal Medicine, 256(3), 183-194.

Ratcliff, R., Thapar, A., Gomez, P., \& McKoon, G. (2004). A diffusion model analysis of the effects of aging in the lexical-decision task. Psychology and Aging, 19(2), 278.

Rider, J. D., Wright, H. H., Marshall, R. C., \& Page, J. L. (2008). Using semantic feature analysis to improve contextual discourse in adults with aphasia. American Journal of Speech-Language Pathology, 17(2), 161-172.

Satz, P. (1993). Brain reserve capacity on symptom onset after brain injury: a formulation and review of evidence for threshold theory. Neuropsychology, 7(3), 273-295.

Schmand, B., Jonker, C., Hooijer, C., \& Lindeboom, J. (1996). Subjective memory complaints may announce dementia. Neurology, 46(1), 121-125.

Shafto, M. A., Burke, D. M., Stamatakis, E. A., Tam, P. P., \& Tyler, L. K. (2007). On the tip-of-the-tongue: neural correlates of increased word-finding failures in normal aging. Journal of Cognitive Neuroscience, 19(12), 2060-2070.

Sorond, F. A., Schnyer, D. M., Serrador, J. M., Milberg, W. P., \& Lipsitz, L. A. (2008). Cerebral blood flow regulation during cognitive tasks: effects of healthy aging. Cortex, 44(2), 179-184.

Troyer, A. K., Moscovitch, M., Winocur, G., Alexander, M. P., \& Stuss, D. 
(1998). Clustering and switching on verbal fluency: the effects of focal frontal-and temporal-lobe lesions. Neuropsychologia, 36(6), 499-504.

Wambaugh, J. L., \& Ferguson, M. (2007). Application of semantic feature analysis to retrieval of action names in aphasia. Journal of Rehabilitation Research \& Development, 44(3), 381-394.
Wambaugh, J. L., Mauszycki, S., Cameron, R., Wright, S., \& Nessler, C. (2013). Semantic feature analysis: incorporating typicality treatment and mediating strategy training to promote generalization. American Journal of SpeechLanguage Pathology, 22(3), S334-S369. 
JungWan Kim, et al. • Effects of Semantic Feature Analysis Treatment in Older Adults

Appendix 1. 어휘산출을 위한 범주별 개방형 유도질문

\begin{tabular}{|c|c|c|c|}
\hline 범주 & 질문 1 & 질문 2 & 질문 3 \\
\hline 꽃 & 어떠한 색깔인가요? & 모양은 어떠한가요? & 어디에서 볼 수 있나요? \\
\hline 옷 & 언제 주로 입나요? & 촉감은 어떠한가요? & 어느 신체와 관련이 있나요? \\
\hline 가구 & 어디에서 볼 수 있나요? & 무엇으로 만들어져 있나요? & 어디에 사용하나요? \\
\hline 교통수단 & 어떠한 기능을 하나요? & 어디에서 볼 수 있나요? & 바퀴는 몇 개인가요? \\
\hline 소지품 & 어떻게 사용하나요? & 어디에 가지고 다니나요? & 어떠한 모양인가요? \\
\hline 동물 & 어떻게 생겼나요? & 어디에서 사나요? & 다리는 몇 개인가요? \\
\hline 주방용품 & 어떻게 사용하나요? & 무엇으로 만들어져 있나요? & 어떠한 모양인가요? \\
\hline 학용품 & 어떻게 사용하나요? & 어떤 모양인가요? & 무엇으로 만들어져 있나요? \\
\hline 채소 & 어떠한 색깔인가요? & 어떻게 먹나요? & 어떠한 모양인가요? \\
\hline 전자제품 & 어떠한 기능이 있나요? & 어디에서 볼 수 있나요? & 크기는 어떠한가요? \\
\hline
\end{tabular}

Appendix 2. 격자표를 활용한 숙제공책 예시

\begin{tabular}{|c|c|c|c|c|c|c|c|c|}
\hline & $\begin{array}{l}\text { 전자제품과 } \\
\text { 관련이 있다 }\end{array}$ & $\begin{array}{l}\text { 부엌이나 } \\
\text { 주방에서 } \\
\text { 볼 수 있다 }\end{array}$ & $\begin{array}{c}\text { 문이 } \\
\text { 달려있다 }\end{array}$ & $\begin{array}{c}\text { 내부에 } \\
\text { 수납공간이 } \\
\text { 있다 }\end{array}$ & $\begin{array}{c}\text { 높이가 } \\
\text { 어른 키보다 } \\
\text { 높다 }\end{array}$ & $\begin{array}{l}\text { 손잡이가 } \\
\text { 달려있다 }\end{array}$ & $\begin{array}{c}\text { 칸막이가 } \\
\text { 있다 }\end{array}$ & $\begin{array}{l}\text { 서랍이 } \\
\text { 있다 }\end{array}$ \\
\hline \multicolumn{9}{|l|}{ 식탁 } \\
\hline \multicolumn{9}{|l|}{ 옷장 } \\
\hline \multicolumn{9}{|l|}{ TV장식대 } \\
\hline 컴퓨터책상 & & & & & & & & \\
\hline
\end{tabular}




\section{국문초록}

\section{의미자질분석 중재에 따른 장노년층의 이름대기 및 인지능력 변화}

김정완 ${ }^{1} \cdot$ 강연욱 ${ }^{2} \cdot$ 이호영 ${ }^{3} \cdot$ 김재현 ${ }^{4} \cdot$ 윤지혜 ${ }^{5}$

${ }^{1}$ 대구대학교 언어치료학과, ${ }^{2}$ 한림대학교 심리학과, ${ }^{3}$ 서울대학교 의과대학 핵의학교실, ${ }^{4}$ 서경대학교 산업경영시스템공학과, ${ }^{5}$ 한림대학교 언어청각학부

배경 및 목적: 단어 찾기 어려움이나 이름대기 장애는 노화과정에서 빈번히 관찰된다. 치매나 인지장애로 진행하기 전, 전임상단계의 장노년층에게 이름대기 어려움에 대한 중재를 실시하여 이름대기 능력을 증진시키고 더 나아가 뇌가소성과 기능적 재조직화의 측면에 서 두뇌 기능을 활성화시킬 수 있다면, 이러한 중재프로그램은 장노년층과 치매 환자들의 의사소통장애를 중재하는 도구로서 사용될 수 있을 뿐만 아니라 인지저하를 예방하는 한 방법이 될 수 있다. 본 연구는 주관적 또는 객관적 이름대기 어려움을 보이는 장노년층을 대상으로 의미자질분석을 활용한 이름대기장애 중재프로그램의 효과를 확인하고자 하였다. 방법: 55-84세 사이의 장노년층 273명을 대상으로 선별검사를 실시한 후, 연구참여를 희망하고 동의한 42 명을 대상으로 보스톤 이름대기검사 규준에 근거하여 이름대기 정상 집단과 비정상 집단으로 구분하였다. 의미범주별 개방형 유도질문과 격자표를 활용한 총 20 회기의 의미자질분석 중재를 실시하였다. 이름대기 및 인지능력에서의 중재효과는 집단(정상/이상집단) 및 검사 시기(사전-사후)의 주효과와 상호작용효과로 비교하였다. 결과: K-BNT의 정반수와 프로브 검사의 정반응수 및 반응시간에서는 사전에 비해 사후 검사의 수행력이 개선되었으나 K-BNT 반응시간에 서는 차이가 없었다. 또한, 인지검사 중, COWAT의 음소유창성, SVLT-E의 즉각회상 및 지연회상 과제에서 사전-사후 검사 간 유의한 수행력 증가가 관찰되었다. 논의 및 결론: 본 연구결과는 장노년층의 이름대기 장애가 전반적인 의미체계상의 네트워크를 활성화하는 방식을 통해 개선될 수 있음을 보여준다.

핵심어: 의미자질분석, 장노년층, 인지, 어휘인출, 활성화

본 논문은 2018년도 한림대학교 교비연구비에 의하여 연구되었음(No. HRF-201810-012).

본 연구는 2014년 정부(교육부)의 재원으로 한국연구재단의 지원을 받아 수행된 연구임(No. NRF-2014S1A5A2A03065709).

\section{참고문헌}

강연욱(2006). K-MMSE (Korean-Mini Mental State Examination)의 노인 규준 연구. 한국심리학회지: 일반, 25(2), 1-12.

김정완, 강연욱, 윤지혜(2015). 55-74세 성인의 명사 범주 규준 조사. Communication Sciences \& Disorders, 20(4), 559-569.

김정완, 황재호, 김수련, 김향희(2013). 정상 노인의 연령에 따른 주의력 및 이름대기 능력의 차이. 언어치료연구, 22(3), 25-44.

모경옥, 성지은, 정지향(2015). 명사 친숙도를 활용한 의미자질중재가 초기 알츠하이머성 치매노인의 이름대기 능력에 미치는 효과. Communication

Sciences \& Disorders, 20(1), 34-47.

오세진, 엄보라, 박채원, 성지은(2016). 실어증 환자를 위한 의미자질 이름대기 중재 효과에 관한 메타 분석. Communication Sciences \& Disorders, 21(2), 310-323.

\section{ORCID}

김정완(http://orcid.org/0000-0003-3763-0914); 강연욱(http://orcid.org/0000-0003-4426-9127); 이호영(http://orcid.org/0000-0001-65180602); 김재현(http://orcid.org/0000-0002-1453-1131); 윤지혜(http://orcid.org/0000-0003-1403-2276) 